\title{
An Interrupted Pummerer/Nickel-Catalysed Cross-Coupling Sequence
}

DOI:

10.1002/anie.201805396

\section{Document Version}

Accepted author manuscript

Link to publication record in Manchester Research Explorer

\section{Citation for published version (APA):}

Aukland, M. H., Talbot, F. J. T., Fernández-salas, J. A., Ball, M., Pulis, A. P., \& Procter, D. J. (2018). An

Interrupted Pummerer/Nickel-Catalysed Cross-Coupling Sequence. Angewandte Chemie International Edition, 57(31). https://doi.org/10.1002/anie.201805396

\section{Published in:}

Angewandte Chemie International Edition

\section{Citing this paper}

Please note that where the full-text provided on Manchester Research Explorer is the Author Accepted Manuscript or Proof version this may differ from the final Published version. If citing, it is advised that you check and use the publisher's definitive version.

\section{General rights}

Copyright and moral rights for the publications made accessible in the Research Explorer are retained by the authors and/or other copyright owners and it is a condition of accessing publications that users recognise and abide by the legal requirements associated with these rights.

\section{Takedown policy}

If you believe that this document breaches copyright please refer to the University of Manchester's Takedown Procedures [http://man.ac.uk/04Y6Bo] or contact uml.scholarlycommunications@manchester.ac.uk providing relevant details, so we can investigate your claim.

\section{OPEN ACCESS}




\title{
An Interrupted Pummerer/Nickel-Catalysed Cross-Coupling Sequence
}

\author{
Miles H. Aukland, ${ }^{[a]}$ Fabien J. T. Talbot,${ }^{[a]}$ José A. Fernández-Salas, ${ }^{[a]}$ Matthew Ball, ${ }^{[b]}$ Alexander P. \\ Pulis, ${ }^{[a]}$ and David J. Procter ${ }^{*[a]}$
}

Abstract: An interrupted Pummerer/Ni-catalysed cross-coupling strategy has been developed and used in the elaboration of styrenes The operationally simple method can be carried out in one-pot, involves the direct formation of stable alkenyl sulfonium salt intermediates, utilises a commercially available sulfoxide, catalyst and ligand, operates at ambient temperature, accommodates $\mathrm{sp}, \mathrm{sp}^{2}$ and $\mathrm{sp}^{3}$-hybridised organozinc coupling partners, and delivers functionalised styrene products in high yields over two-steps. An interrupted Pummerer/cyclisation approach has also been used to access carbo- and heterocyclic alkenyl sulfonium salts for the crosscoupling.

Transition metal-catalysed cross-couplings are an indispensible tool for the construction of carbon-carbon bonds. ${ }^{1}$ In addition to traditional electrophilic partners used in such couplings (e.g. halogens, triflates, etc.), sulfur-based partners have, somewhat surprisingly given their reputation as catalyst poisons, ${ }^{2}$ emerged as willing participants in such transformations and are highly valuable, alternative feedstocks. ${ }^{3-6}$ Recent developments have shown that couplings can be achieved using thiols, sulfides, sulfoxides, sulfones, and sulphonamides. ${ }^{3}$ By comparison, sulfonium salts have been greatly underexploited as coupling partners. ${ }^{4-6}$ In the majority of cases, sulfonium crosscouplings are carried out using palladium catalysts. As the need to move towards the use of inexpensive first row transition metals is now well-appreciated, nickel is an ideal candidate for many metal-catalysed processes due to its low cost and high natural abundance. ${ }^{7}$ Unfortunately, only three isolated examples describe the use of nickel catalysts for the cross-coupling of sulfonium salts (Scheme 1A). ${ }^{4 a, 69}$ In these cases, sulfonium salts are typically accessed from sulfur-containing substrates by alkylation of sulfur. $^{4 a, 6 g}$

Activated sulfoxides are excellent electrophiles and can be used selectively to generate functionality at the expense of $\mathrm{C}-\mathrm{H}$ bonds in aromatic systems via interrupted Pummerer processes. ${ }^{8,9}$ In contrast, analogous interrupted Pummerer reactions of alkenes, that generate alkenyl sulfonium salts, have rarely been exploited in synthesis. ${ }^{10,11}$ We envisaged that, upon treatment with an activated sulfoxide, styrene derivatives would undergo an interrupted-Pummerer process to selectively form alkenyl sulfonium salts and that these crystalline, bench-stable

[a] M. H. Aukland, F. J. T. Talbot, Dr. J. A. Fernández-Salas, Dr. A. P. Pulis, Prof. Dr. David J. Procter

School of Chemistry

University of Manchester

Oxford Road, Manchester, M13 9PL (UK)

E-mail: david.j.procter@manchester.ac.uk

[b] Dr. M. Ball

Pharmaceutical Technology and Development

AstraZeneca

Silk Road Business Park, Macclesfield, SK10 2NA (UK)

Supporting information for this article is given via a link at the end of the document.((Please delete this text if not appropriate)) intermediates could then be employed as electrophilic coupling partners in base metal-catalysed carbon-carbon bond formation. Styrene derivatives are prevalent in a wide variety of pharmaceutical compounds and are ubiquitous in nature (Scheme 1B). ${ }^{12}$ The synthesis of stilbenes is typically achieved through Mizoroki-Heck couplings using palladium catalysts ${ }^{13}$ and the few nickel catalysed processes ${ }^{14}$ require elevated temperatures or specialised catalysts. ${ }^{15}$ Alternatively, substituted stilbenes can be accessed via styrenyl halides ${ }^{16}$ but these can be hard to access ${ }^{17,18}$ and unstable.

\section{A. Previous work: Metal-catalysed cross-coupling of sulfonium electrophiles}

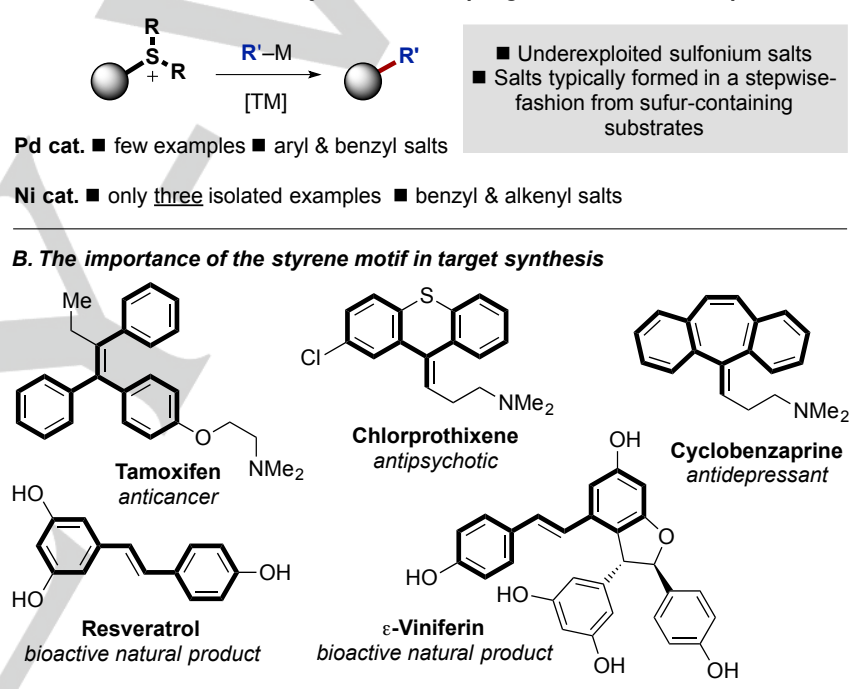

C. This work: Interrupted Pummerer/Ni-catalysed sulfonium cross-coupling Interrupted-Pummerer Novel, bench stable General Ni-catalysed activation $\quad$ sulfonium salts Negishi coupling

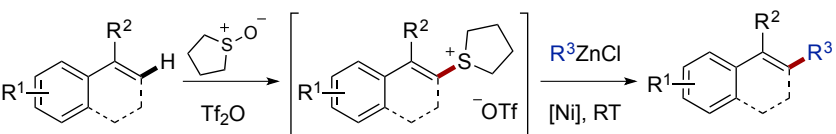

- Salts formed directly from non-sulfur containing substrates Commercial sulfoxide, catalyst and ligand $\square$ Operationally simple $\mathbf{\square}$ One pot Mild conditions - Broad scope of coupling partners

Scheme 1. A. Underexploited sulfonium salts in metal-catalysed crosscoupling. B. Selected bioactive natural and non-natural styrene-containing compounds. C. An interrupted Pummerer/Ni-catalysed cross-coupling strategy.

Herein we report an operationally simple, interrupted Pummerer/Ni-catalysed cross-coupling strategy and its application in the elaboration of styrenes. The sequence has broad scope, exploits bench-stable alkenyl sulfonium salt intermediates formed directly from non-sulfur containing substrates, utilises commercial sulfoxide, catalyst and ligand, and can be carried out in one-pot at ambient temperature (Scheme 1C). An interrupted Pummerer sulfenylation/cyclisation approach has also been developed to access carbo- and heterocyclic alkenyl sulfonium salts for cross-coupling.

We began our studies by investigating the interrupted Pummerer reaction of styrene 1a. Gratifyingly, when 1a was 
treated with either dimethyl sulfoxide (DMSO) or commercial tetrahydrothiophene-S-oxide (THTSO), in combination with triflic anhydride, the corresponding sulfonium salts were formed quantitatively (by ${ }^{1} \mathrm{H} N M R$ ), isolated in excellent yields, and their structures confirmed by X-ray crystallographic analysis (Scheme 2). ${ }^{19}$

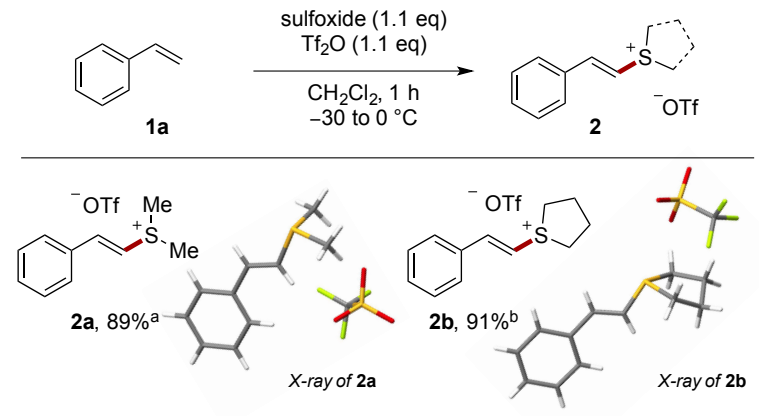

Scheme 2. Direct, convenient and high yielding access to bench stable sulfonium salts: Interrupted Pummerer reactions of styrene with activated sulfoxides. [a] Using DMSO. [b] Using tetrahydrothiophene-S-oxide.

After optimisation of the interrupted Pummerer/Ni-catalysed cross-coupling (see supporting information), a one-pot version of the process was trialled on a variety of styrene derivatives 1a-q and in all cases the coupling products 3a-q were isolated in moderate to excellent yield (Scheme 3). To illustrate the scalability of the process, $\mathbf{3 a}$ was prepared on a gram scale in $82 \%$ overall yield. Substrates bearing alkyl (3b), thiomethyl (3d), halogen $(\mathbf{3 e}-\mathbf{g})$, trifluoromethyl ( $\mathbf{3} \mathbf{h}$ and $\mathbf{3 i})$, and ester $(\mathbf{3 c}$ and $\mathbf{3} \mathbf{j})$ functional groups all underwent smooth sulfenylation and $\mathrm{Ni}$ catalysed coupling with $p$-methoxyphenylzinc chloride. orthoSubstituents did not hinder the efficiency of the process and $\mathbf{3 g}$ and $3 \mathrm{~h}$ were formed in good overall yield. Di-substituted styrenes could also be employed and gave the corresponding tri-substituted alkene products in good yields (3k-m). Pleasingly, the sulfonium salt Negishi cross-coupling occurred selectively even when the substrate contained an alternative pinacolato boron coupling handle (formation of $3 n$ ). Vinyl ferrocene reacted selectively to give 30 in $75 \%$ isolated yield: Ferrocenesubstituted olefins have been investigated for their anticancer activity. ${ }^{20}$ The interrupted Pummerer/Ni-catalysed coupling process can be used to derivatise stilbenes (preparation of 3I) as well as simply to prepare them. Interestingly, upon exposure to the standard conditions, a mixture of $E / Z$ stilbene isomers converges to give a single $E$-sulfonium salt ${ }^{21}$ that then undergoes stereoretentive coupling to give E-3I. Finally, the onepot interrupted Pummerer/Ni-catalysed coupling was used to manipulate complex, biologically-relevant scaffolds: the methyl ester of Bexarotene, an FDA approved antineoplastic agent, ${ }^{22}$ and the complex olefin derived from estrone, underwent the onepot process to give tri-substituted alkene $3 p$ ( $58 \%$ isolated yield, $81 \% \mathrm{brsm})^{23}$ and $\mathbf{3 q}(44 \%$ isolated yield), respectively. The use of $p$-methoxystyrene led to side-products from acid-mediated decomposition.

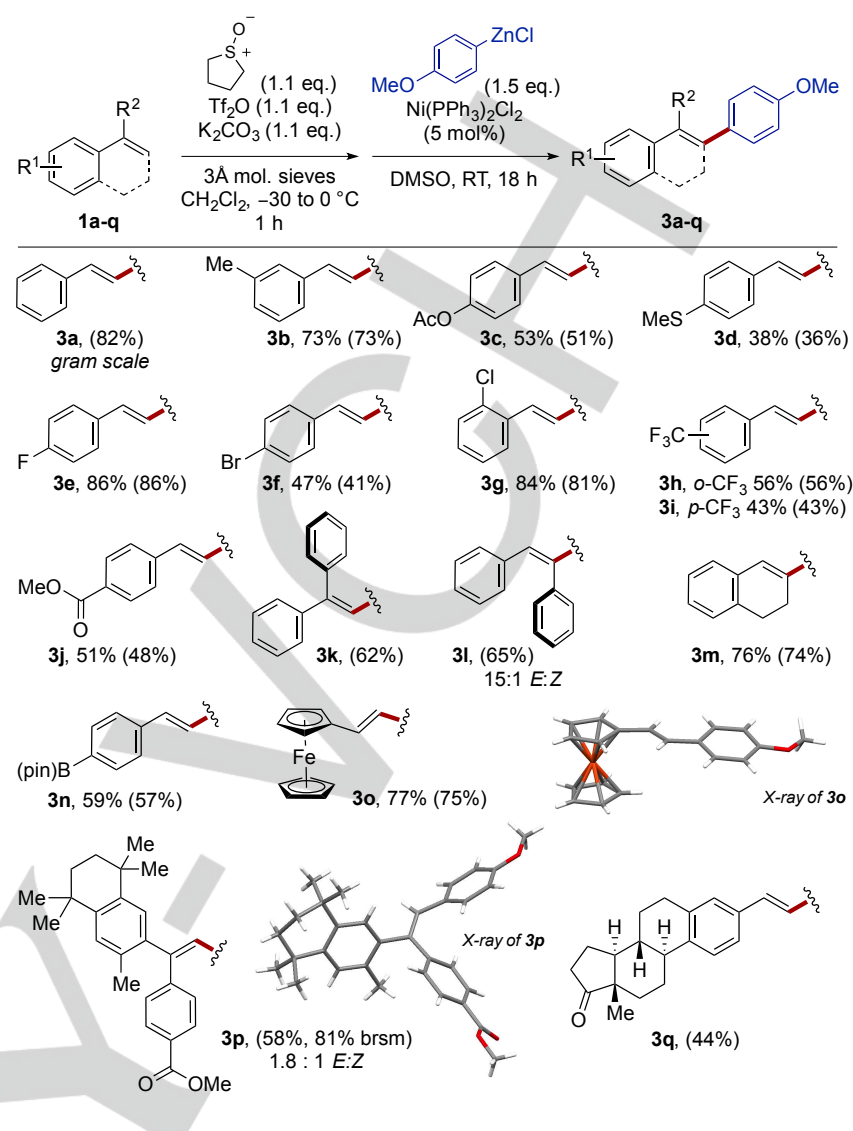

Scheme 3. Scope of the styrene coupling partner in a one-pot, interrupted Pummerer/Ni-catalysed cross-coupling. Yields determined by ${ }^{1} \mathrm{H}-\mathrm{NMR}$ using $\mathrm{MeNO}_{2}$ as internal standard. Isolated yields in parentheses.

Using para-fluorostyrene, we next assessed the scope of the interrupted Pummerer/Ni-catalysed coupling from the perspective of the nucleophilic organozinc coupling partner (Scheme 4). Ortho-, meta-, and para-substituted arylzinc reagents were all successfully coupled to give products $3 r-y$ in good to excellent yield. The presence of sensitive functionalities did not hamper the reaction; for example, nitrile $\mathbf{3 v}$ and heteroaryl products $3 \mathbf{a b}$ and $3 \mathbf{a c}$ were obtained in good yield. In addition to aryl organozinc reagents, $s p^{3}$-hybridised organozincs proved to be competent coupling partners; the use of primary and secondary alkylzincs delivered the expected coupling products in good overall yield (3z, 3ad and 3ae). Similarly, alkynylzinc reagents were shown to be effective partners (3af and 3ag) and their use enabled convenient access to conjugated enyne motifs; structures of interest due to their presence in various bioactive marine natural products. ${ }^{24}$ 


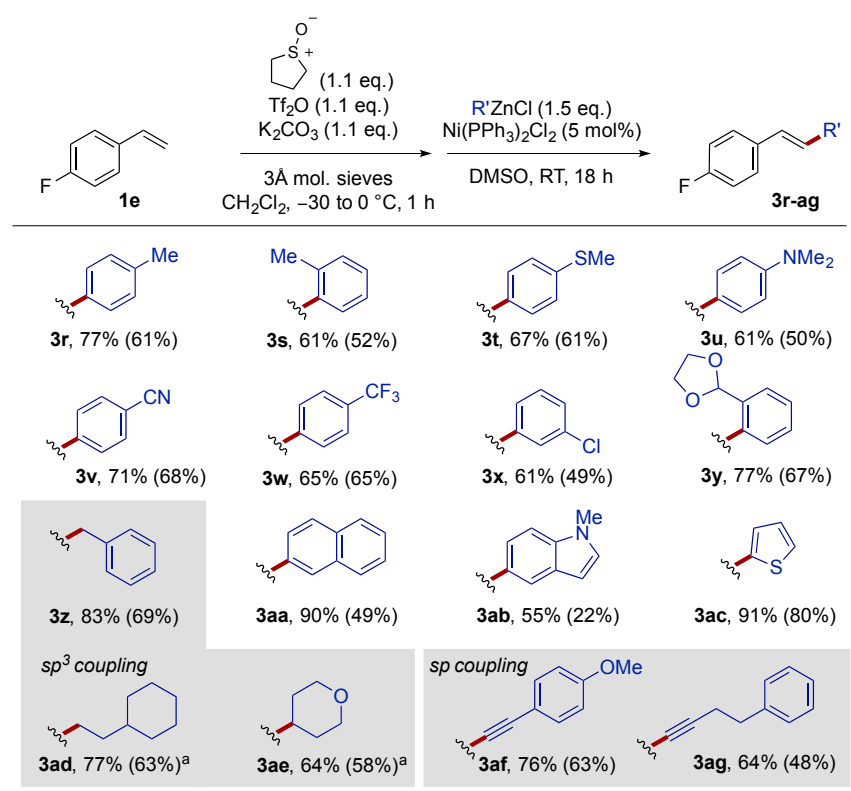

Scheme 4. Scope of the organozinc coupling partner in a one-pot, interrupted Pummerer/Ni-catalysed cross-coupling. Yields determined by ${ }^{1} \mathrm{H}$ NMR using $\mathrm{MeNO}_{2}$ internal standard. Isolated yields in parentheses. [a] $10 \mathrm{~mol} \%$ $\mathrm{Ni}\left(\mathrm{PCy}_{3}\right)_{2} \mathrm{Cl}_{2}$ used

Metal-free activation of the alkenes proceeds via an interrupted Pummerer pathway in which the styrenyl double bond acts as a nucleophile and attacks the activated sulfoxides at sulfur. ${ }^{9}$ Subsequent deprotonation of the cationic intermediates A generates bench stable, crystalline alkenyl sulfonium salts (Scheme 5A). The cross-coupling likely involves in situ formation of a low-valent nickel species and oxidative addition into the $\mathrm{C}-\mathrm{S}$ bond to give $\mathrm{Ni}$ (II) intermediates $\mathbf{B}^{25,26}$ Following transmetallation, reductive elimination from intermediate $\mathbf{C}$ delivers the coupling product (Scheme 5B).
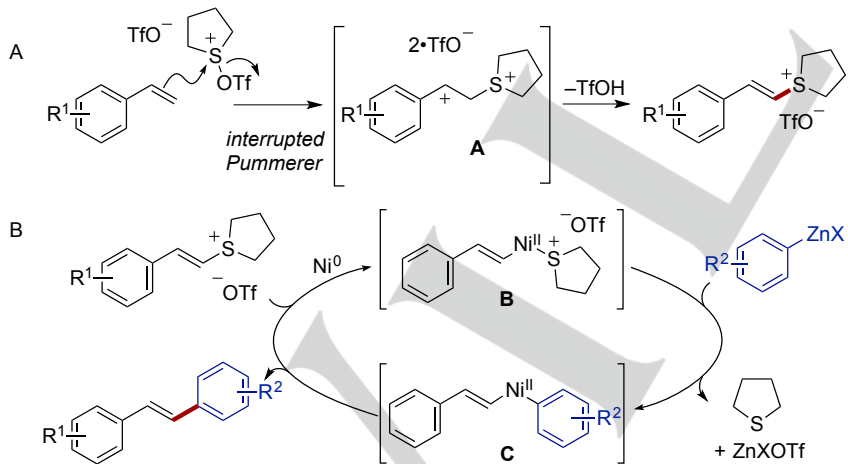

Scheme 5. Mechanistic proposal for the two stages of the interrupted Pummerer/Ni-catalysed cross-coupling sequence.

We have carried out preliminary studies on extending the approach to alternative $\pi$-nucleophiles. Arene $\mathbf{4}$ underwent regioselective sulfenylation and $\mathrm{Ni}$-catalysed cross-coupling of the resultant aryl sulfonium salt $\mathbf{5}$ with $p$-methoxyphenylzinc chloride gave 6 in $62 \%$ overall yield. Similarly, phenylacetylene 7 underwent interrupted Pummerer/Ni-catalysed cross-coupling to give 9 in moderate yield via alkynyl sulfonium salt 8 (Scheme 6). ${ }^{27}$

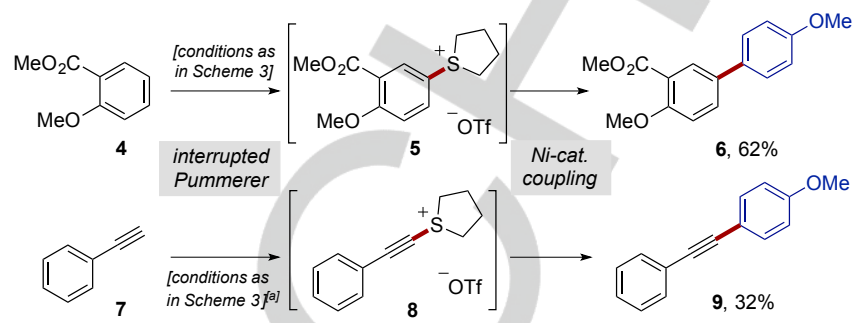

Scheme 6. Extension of the interrupted Pummerer/Ni-catalysed crosscoupling strategy to arene and alkyne coupling partners. [a] 2.2 equiv. $\mathrm{K}_{2} \mathrm{CO}_{3}$ used.

Finally, subjecting aryl-containing alkyne $10 \mathrm{a}$ to the interrupted Pummerer conditions triggered cyclisation ${ }^{28}$ and alkenyl sulfonium salt 11a was obtained in $84 \%$ isolated yield. Due to the greater steric encumbrance of the $\mathrm{C}-\mathrm{S}$ bond in trisubstituted 12a, a short optimisation study was required to identify conditions for the Ni-catalysed cross-coupling of these salts with aryl zinc reagents (see supporting information): The combination of nickel(II) chloride and JohnPhos proved optimal for the coupling and tetra-substituted olefin $12 \mathrm{a}$ was isolated in $80 \%$ yield.
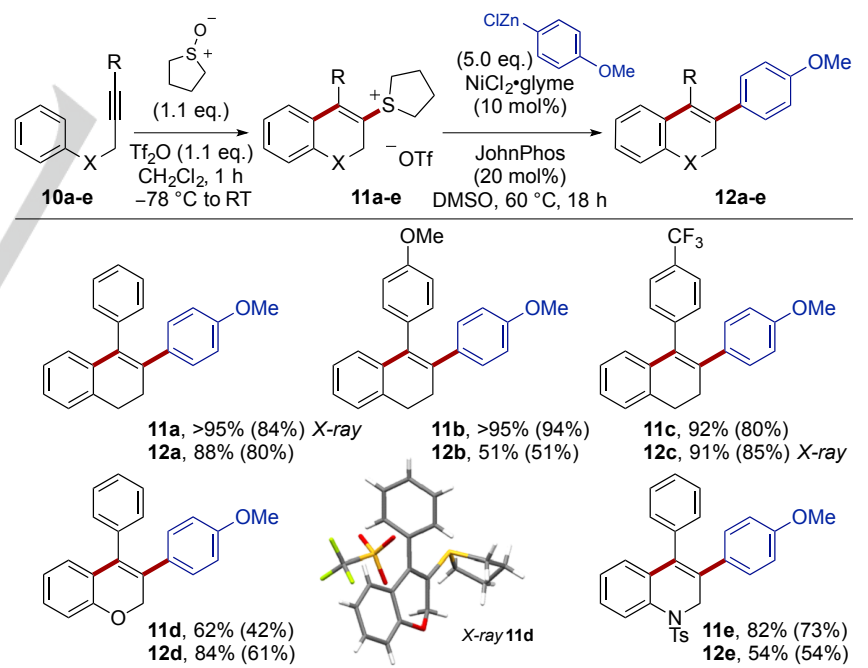

Scheme 8. Scope of the interrupted Pummerer/cyclisation/Ni-catalysed crosscoupling sequence. Yields determined by ${ }^{1} \mathrm{H}-\mathrm{NMR}$ using a $\mathrm{MeNO}_{2}$ internal standard. Isolated yields in parentheses.

Bench stable alkenylsulfonium salts $11 \mathrm{~b}$-e were next prepared from the corresponding alkynes $10 \mathrm{~b}-\mathrm{e}$ and utilised in the $\mathrm{Ni}$-catalysed cross-coupling to give products $12 \mathrm{~b}-\mathrm{e}$ in moderate to high overall, isolated yield. The structure of sulfonium salt $11 \mathrm{~d}$ was confirmed by $\mathrm{X}$-ray crystallographic analysis. Both electron-donating and electron-withdrawing substituents were tolerated (formation of $\mathbf{1 2 b}$ and $\mathbf{1 2 c}$ ), as were heteroatoms in the tether between alkyne and arene: The later 
substrates delivered heterocyclic products $12 \mathrm{~d}$ and $12 \mathrm{e}$ in good yield.

In summary, an interrupted Pummerer process, using a readily available sulfoxide, activates styrenes under metal-free conditions. The resulting bench stable alkenyl sulfonium salts undergo Ni-catalysed Negishi cross-coupling with commercial ligands and catalysts to give high value products. The versatile sequence can be carried out in one-pot, embraces a range of organozinc partners, and can form di-, tri-, and tetra-substituted alkene products. Finally, interrupted Pummerer activation and sulfonium salt formation can be extended to arenes and alkynes, and in the later case, has been used to simultaneously trigger cyclisation.

\section{Acknowledgements}

We thank EPSRC (Postdoctoral Fellowship to J.A.F.-S.; Established Career Fellowship to D.J.P.), The University of Manchester (Lectureship to A.P.P.), AstraZeneca (Studentship to M.H.A.), and Erasmus+ and bourse boussole (Internship to F.J.T.T.) for their generous support.

Keywords: Pummerer $\cdot$ sulfoxide $\cdot$ sulfonium salt $\cdot$ nickel catalysis $\cdot$ cross-coupling

[1] C. C. C. Johansson Seechurn, M. O. Kitching, T. J. Colacot, V. Snieckus, Angew. Chem. Int. Ed. 2012, 51, 5062-5085.

[2] a) J. Dunleavy, Platinum Metals Rev. 2006, 50, 110-110; b) N. S. Nasri, J. M. Jones, V. A. Dupont, A. Williams, Energy \& Fuels 1998, 12, 1130 1134; c) X. Tiancun, A. Lidun, Catal. Lett. 1992, 12, 287-296.

[3] a) Z-Y. Tian, Y-T. Hu, H-B. Teng, C-P. Zhang, Tetrahedron Lett. 2018, 59, 299-309; b) F. Pan, Z-J. Shi, ACS Catal. 2014, 4, 280-288; c) L. Wang, W. He, Z. Yu, Chem. Soc. Rev. 2013, 42, 599-621; d) S. G. Modha, V. P. Mehtaz, E. V. Van der Eycken, Chem. Soc. Rev. 2013, 42 5042-5055; e) S. R. Dubbaka, P. Vogel, Angew. Chem. Int. Ed. 2005, 44, 7674-7684; f) T-Y. Luh, Z-J. Ni, Synthesis 1990, 89-103.

[4] a) S. Zhang, D. Marshall, L. S. Liebeskind, J. Org. Chem. 1999, 64 2796-2804; b) J. Srogl, G. D. Allred, L. S. Liebeskind, J. Am. Chem. Soc. 1997, 119, 12376-12377.

[5] a) H. Minami, S. Otsuka, K. Nogi, H. Yorimitsu, ACS Catal. 2018, 8, 579-583; b) H. Kawashima, T. Yanagi, C-C. Wu, K. Nogi, H. Yorimitsu, Org. Lett. 2017, 19, 4552-4555; c) D. Vasu, H. Yorimitsu, A. Osuka, Synthesis 2015, 47, 3286-3291; d) D. Vasu, H. Yorimitsu, A. Osuka, Angew. Chem. Int. Ed. 2015, 54, 7162-7166.

[6] a) Z-Y. Tian, S-M. Wang, S-J. Jia, H-X. Song, C-P. Zhang, Org. Lett. 2017, 19, 5454-5457; b) S-M. Wang, X-Y. Wang, H-L. Qin, C-P. Zhang Chem. - Eur. J. 2016, 22, 6542-6546; c) X-Y. Wang, H-X. Song, S-M. Wang, J. Yang, H-L. Qin, X. Jiang, C-P. Zhang, Tetrahedron 2016, 72, 7606-7612; d) S-M. Wang, H-X. Song, X-Y. Wang, N. Liu, H-L. Qin, CP. Zhang, Chem. Commun. 2016, 52, 11893-11896; e) P. Cowper, Y. Jin, M. D. Turton, G. Kociok-Köhn, S. E. Lewis, Angew. Chem. Int. Ed. 2016, 55, 2564-2568; f) P. Cowper, A. Pockett, G. Kociok-Köhn, P. J. Cameron, S. E. Lewis, Tetrahedron 2018, 74, 2775-2786; g) J. F. Hooper, A. B. Chaplin, C. González-Rodríguez, A. L. Thompson, A. S. Weller, M. C. Willis, J. Am. Chem. Soc. 2012, 134, 2906-2909; h) H. Lin, X. Dong, Y. Li, Q. Shen, L. Lu, Eur. J. Org. Chem. 2012, 4675-4679; i) C. Vanier, F. Lorgé, A. Wagner, C. Mioskowski, Angew. Chem. Int. Ed. 2000, 39, 1679-1683.

[7] S. Z. Tasker, E. A. Standley, T. F. Jamison, Nature 2014, 509, 299-309.
[8] a) N. E. Shevchenko, V. G. Nenajdenko, E. S. Balenkova, Synthesis 2003, 8, 1191-1200; b) N. E. Shevchenko, A. S. Karpov, E. P. Zakurdaev, V. G. Nenajdenko, E. S. Balenkova, Chem. Heterocycl. Compd. 2000, 36, 137-143; c) V. G. Nenajdenko, P. V. Vertelezkij, E. S. Balenkova, Sulfur Lett. 1996, 20, 75-84.

[9] a) H. Yorimitsu, Chem. Rec. 2017, 17, 1-13; b) A. P. Pulis, D. J. Procter, Angew. Chem. Int. Ed. 2016, 55, 9842-9860; c) L. H. S. Smith, S. C. Coote, H. F. Sneddon, D. J. Procter, Angew. Chem. Int. Ed. 2010, 49, 5832-5844.

[10] a) V. G. Nenajdenko, P. V. Vertelezkij, I. D. Gridnevt, N. E. Shevchenko, E. S. Balenkova, Tetrahedron 1997, 53, 8173-8180; b) J-I. Matsuo, H. Yamanaka, A. Kawana, T. Mukaiyama, Chemistry Lett. 2003, 32, 392393; For the interrupted Pummerer reaction of an alkene to give an allylsulfonium salt, see: c) G. Hu, J. Xu, P. Li, Org. Lett. 2014, 16, 60366039; d) V. V. Veselovsky, V. A. Dragan, A. M. Moiseenkov, Tetrahedron Lett. 1988, 29, 6637-6639; e) B. B. Snider, N. J. Hrib, L. Fuzesi, J. Am. Chem. Soc. 1976, 98, 7115-7117.

[11] For the synthetic exploitation of aryl sulfonium salts, see: a) D. Kaldre, B. Maryasin, D. Kaiser, O. Gajsek, L. González, N. Maulide, Angew. Chem. Int. Ed. 2017, 56, 2212-2215; b) T. Stopka, M. Niggemann, N. Maulide, Angew. Chem. Int. Ed. 2017, 56, 13270-13274; c) D. Kaiser, L. F. Veiros, N. Maulide, Adv. Synth. Catal. 2017, 359, 64-77; d) H. J. Shrives, J. A. Fernández-Salas, C. Hedtke, A. P. Pulis, D. J. Procter, Nat. Commun. 2017, 8, 14801-14808; e) T. Yanagi, S. Otsuka, Y. Kasuga, K. Fujimoto, K. Murakami, K. Nogi, H. Yorimitsu, A. Osuka, J. Am. Chem. Soc. 2016, 138, 14582-14585; f) D. Kaiser, L. F. Veiros, N. Maulide, Chem. - Eur. J. 2016, 22, 4727-4732; g) J. A. FernándezSalas, A. J. Eberhart, D. J. Procter, J. Am. Chem. Soc. 2016, 138, 790793; h) J. A. Fernández-Salas, A. P. Pulis, D. J. Procter, Chem. Commun. 2016, 52, 12364-12367; i) A. J. Eberhart, H. J. Shrives, E. Alvarez, A. Carrer, Y. Zhang, D. J. Procter, Chem. - Eur.J. 2015, 21, 7428-7434; j) B. Peng, D. Geerdink, C. Farès, N. Maulide, Angew. Chem. Int. Ed. 2014, 53, 5462-5466; k) B. Peng, X. Huang, L-G. Xie, N. Maulide, Angew. Chem. Int. Ed. 2014, 53, 8718-8721; I) X. Huang, M. Patil, C. Farès, W. Thiel, N. Maulide, J. Am. Chem. Soc. 2013, 135, 7312-7323; m) A. J. Eberhart, D. J. Procter, Angew. Chem. Int. Ed. 2013, 52, 4008-4011; n) A. J. Eberhart, C. Cicoira, D. J. Procter, Org Lett. 2013, 15, 3994-3997; o) X. Huang, S. Klimczyk, N. Maulide, Synthesis 2012, 44, 175-183; p) X. Huang, N. Maulide, J. Am. Chem. Soc. 2011, 133, 8510-8513; q) A. J. Eberhart, J. E. Imbriglio, D. J. Procter, Org. Lett. 2011, 13, 5882-5885.

[12] a) S. Bradamante, L. Barenghi, A. Villa, Cardiovasc. Drug Rev. 2004, 22, 169-188; b) B. B. Aggarwal, A. Bhardwaj, R. S. Aggarwal, N. P. Seeram, S. Shishodia, Y. Takada, Anticancer Res. 2004, 24, 27832840.

[13] a) F-X. Felpin, L. Nassar-Hardy, F. Le Callonnec, Eric Fouquet, Tetrahedron 2011, 67, 2815-2831; b) I. P. Beletskaya, A. V. Cheprakov, Chem. Rev. 2000, 100, 3009-3066.

[14] B. Lin, L. Liu, Y. Fu, S-W. Luo, Q. Chen, Q-X. Guo, Organometallics 2004, 23, 2114-2123.

[15] a) N. Nowrouzi, M. Zarei, Tetrahedron 2015, 71, 7847-7852; b) P. K. Suganthya, R. N. Prabhub, V. S. Sridevi, Tetrahedron Lett. 2013, 54, 5695-5698; c) A. R. Ehle, Q. Zhou, M. P. Watson, Org. Lett. 2012, 14, 1202-1205; d) Z. Xi, B. Liu, W. Chen, J. Org. Chem. 2008, 73, 39543957; e) S. Ma, H. Wang, K. Gao, F. Zhao, J. Mol. Catal. A: Chem. 2006, 248, 17-20.

[16] For an example of a Negishi coupling of styrenyl bromide, see: A. Gavryushin, C. Kofink, G. Manolikakes, P. Knochel, Tetrahedron 2006 62, 7521-7533.

[17] a) M. J. Koh, T. T. Nguyen, H. Zhang, R. R. Schrock, A. H. Hoveyda, Nature 2016, 531, 459-465; b) P. Pawluć, G. Hreczycho, J. Szudkowska, M. Kubicki, B. Marciniec, Org. Lett. 2009, 11, 3390-3393; c) C. Morrill, R. H. Grubbs, J. Org. Chem. 2003, 68, 6031-6034. d) K. Takai, K. Nitta, K. Utimoto, J. Am. Chem. Soc. 1986, 108, 7408-7410.

[18] M. R. Kuszpit, M. B. Giletto, C. L. Jones, T. K. Bethel, J. J. Tepe, J. Org. Chem. 2015, 80, 1440-1445 
[19] CCDC 1832461 (2a), 1832460 (2b), 1832454 (3o), 1832463 (E-3p), 1832462 (11a), 1836658 (11d) and 1836657 (11c)

[20] a) A. Nguyen, S. Top, P. Pigeon, A. Vessieres, E. A. Hillard, M-A. Plamont, M. Huche, C. Rigamonti, G. Jaouen, Chem. - Eur. J. 2009, 15, 684-696; b) Y. Leng K. Tan, P. Pigeon, E. A. Hillard, S. Top, M-A Plamont, A. Vessieres, M. J. McGlinchey, H. Muller-Bunzb, G. Jaouen, Dalton Trans. 2009, 10871-10881; c) O. Buriez, J. M. Heldt, E. Labbe, A. Vessieres, G. Jaouen, C. Amatore, Chem. - Eur. J. 2008, 14, 81958203.

[21] Stereochemistry of the alkene was confirmed by NMR analysis and nOe studies.

[22] R. Gniadecki, C. Assaf, M. Bagot, R. Dummer, M. Duvic, R. Knobler, A Ranki, P. Schwandt, S. Whittaker, Brit. J. Dermatol. 2007, 157, 433-440.

[23] Confirmed by NMR and X-ray crystallographic analysis.
[24] D. J. Faulkner, Nat. Prod. Rep. 1999, 16, 155-198.

[25] E. Wenkert, M. E. Shepard, A. T. McPhail, J. Chem. Soc., Chem Commun. 1986, 1390-1391.

[26] M. R. Grochowski, T. Li, W. W. Brennessel, W. D. Jones, J. Am. Chem Soc. 2010, 132, 12412-12421.

[27] V. G. Nenajdenko, P. V. Vertelezkij, E. S. Balenkova, Synthesis 1997 351-355.

[28] Intramolecular carbosulfenylation of alkenes: a) Z. Tao, K. A. Robb, K. Zhao, S. E. Denmark, J. Am. Chem. Soc. 2018, 140, 3569-3573; b) F. T. Schevenels, M. Shen, S. A. Snyder, Org. Lett. 2017, 19, 2-5. 


\section{Entry for the Table of Contents}

\section{COMMUNICATION}

Interrupted-Pummerer activation Ni-catalysed Negishi coupling

$\mathrm{R}^{1}$<smiles>[R]C1=CCCc2ccncc21</smiles><smiles>CC(C)CO</smiles><smiles>[R11]=CCC</smiles><smiles>[R]c1cccc2ccccc12</smiles>

isolate or one-pot

\section{$\mathrm{R}^{2}$}

$\mathrm{R}^{3} \mathrm{ZnCl}$

[Ni], RT<smiles>[R]C1=C([R])c2cc[R1]([H])cc2CC1</smiles>

Styrenes are activated under metal-free conditions using an interrupted Pummerer process. The resulting, stable alkenyl sulfonium salts undergo Ni-catalysed crosscoupling under simple, mild conditions. The versatile sequence can be carried out in one-pot, embraces a range of organozinc partners, and can form di-, tri-, and tetra-substituted alkene products. Interrupted Pummerer activation of alkynes can also trigger cyclisation and the formation of carbo- and heterocyclic alkenyl sulfonium salts for cross-coupling.

Miles H. Aukland, Fabien J. T. Talbot, José A. Fernández-Salas, Matthew Ball, Alexander P. Pulis and David J. Procter*

Page No. - Page No.

An Interrupted Pummerer/NickelCatalysed Cross-Coupling Sequence for the Elaboration of Styrenes 